\title{
LOS CLÍTICOS MARGINALES Y EL COMPONENTE DE MANERA
}

Antonio Fábregas

\section{(c) ${ }_{\mathrm{EY}} \mathrm{NO} \mathrm{ND}_{\mathrm{ND}}$}

Doi: https://doi.org/10.15517/rfl.v44i2.34694

URL: https://revistas.ucr.ac.cr/index.php/filyling 



\title{
LOS CLÍTICOS MARGINALES Y EL COMPONENTE DE MANERA
}

\author{
MARGINAL CLITICS AND THE MANNER COMPONENT
}

\author{
Antonio Fábregas ${ }^{1}$
}

\begin{abstract}
RESUMEN
Este trabajo estudia los llamados clíticos marginales que forman parte de ciertas construcciones idiomáticas de naturaleza verbal (jorobarla , tomarla , pirárselas, jugársela $\underline{\text { a }}$ ), concentrándose en dos aspectos de su gramática: su contribución de significado y la tendencia a aparecer como formas femeninas. Se propone que en ambos casos la respuesta se relaciona con la presencia de un sustantivo omitido de manera cuya contribución semántica es perceptible pese a la naturaleza idiomática de la construcción: el clítico pronominaliza rasgos de este sustantivo, bajo condiciones muy específicas que no son exclusivas de esta clase de construcciones.

Palabras clave: clíticos, construcciones idiomáticas, manera, composicionalidad, femenino.
\end{abstract}

\begin{abstract}
This work addresses so-called marginal clitics, clitics that are part of several verbal idioms (jorobarla 'to spoil something', tomarla 'to get angry with someone', pirárselas 'to leave quickly', jugársela 'to risk'), concentrating on two aspects of their grammar: their meaning contribution and their tendency to occur as feminine forms. It is argued that in both cases the answer relates to the presence of a silent noun of manner whose semantic contribution is perceptible despite the idiomatic nature of the construction: the clitic pronominalises features of this noun, under very specific conditions that are not exclusive of this type of constructions.
\end{abstract}

Key words: clitics, idiomatic constructions, manner, compositionality, feminine.

\section{Introducción: los clíticos marginales}

Los llamados clíticos marginales, inherentes, idiomáticos o no referenciales han recibido cierta atención en la bibliografía fraseológica, semántica y sintáctica (Ruiz Gurillo, 1997, 2009; Mendívil, 1999; Bibis, 2002; Bibis y Roberge, 2004; Espinal, 2009; RAE \& ASALE, 2009, p. $\S$ 34.11b-d; García Page, 2010; Leivada \& Grohmann, 2014; Cifuentes Honrubia, 2017; Cordero Monge y Leoni de León, 2017; Silva Garcés, 2017). Se ilustran algunas construcciones propias del español europeo en (1), donde se subraya el clítico marginal:

Dr. Antonio Fábregas. University of Troms $\varnothing$, Full Professor, Spanish Linguistics. Noruega.

Correo electrónico: antonio.fabregas@uit.no

Recepción: 02- 02- 2018

Aceptación: 15- 05- 2018 
(1)
a. pasarlo / pasarla (bien)
b. diñarla
c. arreglárselas
d. creérselo
e. fliparlo
f. tomarla (con alguien)
g. jorobarla

Véase García Page (2010) y Cifuentes Honrubia (2017) para una lista más exhaustiva. Asimismo, en algunas variedades estos clíticos marginales son enormemente productivos y no se restringen a construcciones de significado impredecible. Silva Garcés (2017) observa que en la variedad argentina aparecen estos clíticos marginales en casos como (2), donde están siempre asociados a la lectura de 'comportarse de una manera especificada por la base verbal':
a. rockearla
b. cuchichearla
c. parrandearla
d. tontearla
e. secretearla

La estructura del resto de este trabajo es la siguiente: en el resto de esta sección nos concentraremos en tres problemas relacionados con estas construcciones idiomáticas y en los que concentraremos nuestra investigación. En la segunda parte, resumiremos las propiedades sintácticas y semánticas de los clíticos marginales, y también las propiedades morfológicas, sintácticas y semánticas de los verbos con los que se combinan. Esto nos permitirá dar una serie de propiedades -algunas de ellas, hasta donde se nos alcanza, no observadas en la bibliografía previa- que nos llevará, en la tercera parte, a proponer un análisis donde la presencia del clítico se relaciona con un sustantivo MANERA que está presente en otras construcciones del español. En el punto 4, se presenta la forma en que la estructura de manera se integra con el verbo, dando cuenta de las propiedades notadas en la segunda parte, y discute las condiciones bajo las cuales se produce la pronominalización. Finalmente, en la quinta parte, se presenta las conclusiones fundamentales del trabajo.

En esta revisión seguiremos estréchamente la propuesta de Espinal (2009) por dos motivos: frente a los otros trabajos que se han centrado en el caso del español, se concentra en aspectos estructurales más que lexicográficos o morfológicos, y se ha ocupado específicamente de la misma lengua en la que trabajamos nosotros, por lo que es el antecedente más directo de esta investigación.

\subsection{La semántica del clítico}

En primer lugar, se discute cuál es -si es que la tiene- la contribución semántica del clítico marginal. Algo en lo que todos los trabajos, independientemente de su orientación teórica, están de acuerdo (cf. para una discusión detallada de este punto Mendívil, 1999; Bibis y Roberge, 2004; Espinal, 2009; Leivada y Grohmann, 2014) es en que estos clíticos no son referenciales, frente al proceso de cliticización habitual. Podemos contrastar (3) con (4): en (3) tenemos una interpretación composicional donde hay un uso estándar del clítico con capacidad de referir a una expresión anterior, que en este caso es el sintagma nominal ese día. No hay 
ninguna interpretación idiomática disponible en este caso, y además los rasgos de género y número del clítico dependen de los que tiene la expresión a la que refiere (cf. también Espinal, 2009 para una discusión más detallada).

$$
\begin{aligned}
& \text { Ese día } \text { lo }_{\mathrm{i}} \text { pasé inquieto. [blogsdelagente, ap. Corpus del Español] } \\
& \text { ('Durante ese día estuve inquieto', cf. Pasé ese día inquieto.) }
\end{aligned}
$$

En cambio, en (4) tenemos la construcción con el clítico marginal, con la lectura idiomática y en ella no hay correferencia posible. Los rasgos del clítico no dependen de los de otra expresión presente en el discurso, ya que el clítico no refiere a expresión alguna. Nótese que, en las variedades donde la expresión idiomática es pasarla, ${ }^{2}$ (4) implicaría el uso del clítico la mientras que en (3) seguiría usándose lo.

$$
\begin{aligned}
& \text { Ese día lo pasaron muy bien. [diariored.mx, ap. Corpus del español] } \\
& \text { ('Ese día nos divertimos') }
\end{aligned}
$$

Tampoco parece posible asociar el clítico a alguna expresión sobreentendida, algo potencialmente concebible en algunos casos (cf. RAE y ASALE, 2009, p. §34.11b, donde se señala que el clítico de (4) podría relacionarse con una expresión como 'el tiempo', si bien eso no permitiría explicar el contraste interpretativo entre el significado del verbo en (3) y (4)), pero muy discutible en otros: ¿a qué entidad referiría el clítico en una expresión como pirárselas? Finalmente en estos casos tampoco hay siempre una interpretación temática clara que el verbo imponga al clítico, como paciente, beneficiario o cualquier otra lectura: ¿a qué papel temático correspondería por ejemplo el clítico en diñarla, cuando la mayoría de los hablantes no pueden emplear el verbo diñar aisladamente?

Si el clítico no tiene referencia, cabría proponer que se trata de un expletivo, pero esta hipótesis ha sido rechazada porque, de ser así, estos clíticos se comportarían de forma excepcional entre los expletivos del español. El primero de ellos es que normalmente el español no materializa de forma explícita los pronombres expletivos. Hay acuerdo general en que el sujeto de un verbo meteorológico como el de (5) es expletivo (cf. por ejemplo Fernández Soriano y Táboas, 1999). Una propiedad de estos elementos expletivos en español es que deben permanecer tácitos en la inmensa mayoría de las variedades contemporáneas.

$$
\begin{aligned}
& \text { a. (*Ello) llueve. } \\
& \text { b. (*Ello) hace frío. }
\end{aligned}
$$

Por tanto, si los clíticos de las expresiones idiomáticas estudiadas aquí fueran expletivos, resultarían ser los únicos expletivos que en español no son tácitos de forma general. Por estos motivos, se han propuesto distintas posibilidades para asignarles un significado. Espinal (2009) los trata como variables libres sobre objetos abstractos -proposiciones, situaciones espacio-temporales sin referencia, propiedades de diverso tipo-, que precisamente por el carácter inespecífico de los objetos que denotan tienen que sufrir un proceso de incorporación al predicado. Leivada y Grohmann (2014) proponen que los clíticos de las construcciones idiomáticas solo carecen de referencia aparentemente, porque la información conceptual de la estructura no permite percibirla directamente -tratando, así, el clítico marginal como un clítico estándar-. Bibis y Roberge (2002) proponen que el clítico marginal carece de propiedades de determinante, lo cual le impide ser referencial, pero a cambio posee información semánticamente interpretable dentro del contexto de la estructura idiomática. 
En este trabajo, como se verá, argumentaremos que el clítico corresponde a la pronominalización de un sustantivo silencioso (Kayne, 2005a) que denota manera, y representaremos este sustantivo como MANERA para diferenciarlo de su versión con contenido fonológico.

\subsection{La fijación morfológica del clítico}

La segunda pregunta que ha atraído la atención de los investigadores de este fenómeno es la aparente fijación del clítico en género, número y caso. Los ejemplos del español siempre implican caso acusativo, pero en griego moderno y en griego chipriota hay otras estructuras fijadas en genitivo (Leivada y Grohmann, 2014). Por ejemplo, el clítico marginal de (6) está fijado en femenino singular, y rechaza las formas de primera o segunda persona; cuando aparecen las demás formas, la lectura idiomática desaparece.
a. pringarla ('verse involucrado en un trabajo enojoso') $)^{3}$
b. \#pringarme ('mancharme con pringue')
c. \#pringarlas ('mancharlas con pringue')
d. \#pringarlo ('mancharlo con pringue')

Hay diversas observaciones que se han hecho sobre este aspecto. Leivada y Grohman (2014) notan que esta fijación no sucede en todos los casos, y que ciertas construcciones admiten más de una forma; igualmente, esto es observado para el español por García Page (2010), que menciona el caso de doblarla / doblarlas ('morir') o Me \{la / las\} vas a pagar ('vas a rendir cuentas ante mí') aunque anotando que en la mayor parte de los casos dicha alternacia, de darse, da lugar a dos construcciones distintas, como en liarla 'provocar un lío' frente a liarlas 'morir'. Bibis y Roberge (2004) hacen de esta propiedad una característica central de los clíticos marginales, ya que en su análisis contrastan con los clíticos estándar en que solo estos últimos establecen relaciones de concordancia con un antecedente, mientras que los marginales vienen equipados ya con un conjunto de rasgos formales invariables, como los sustantivos. Contra la propuesta de que el clítico y el verbo forman una única unidad listada de forma invariable tenemos, por ejemplo, el argumento de que en perífrasis es posible separar el verbo del clítico mediante el auxiliar:

$$
\text { Si sale con sangre, la va a espichar. }
$$

[soledadentretenida.blogspot.com, ap. Corpus del español]

\subsection{La relación entre el femenino y las construcciones idiomáticas de manera}

Esto nos lleva a la tercera pregunta, que es la tendencia marcada en español a que esta clase de clíticos aparezcan en forma femenina, singular o plural. En la siguiente lista no exhaustiva se dan varios ejemplos, y añadimos la observación de que en la variedad argentina discutida en Silva Garcés (2017) el clítico siempre tiene que ser femenino.

(8) agarrarla, agenciárselas, apañárselas, armarla, arreglárselas, buscársela, cagarla, cantarlas claras, cargársela, cazarlas al vuelo, chocarla, cogerla, colársela, componérselas, correrla, dársela con queso, deberle una, diñarla, doblarla, emprenderla con alguien, entendérselas con alguien, espicharla, gastarlas, gozarla, guardársela, 
habérselas con alguien, ingeniárselas, jeringarla, joderla, jorobarla, jugársela, jugárselo todo a una carta, liarla, pagárselas, palmarla, pasarlas negras, pegársela, pifiarla, pirárselas, pringarla, prometérselas felices, soplársela, tenérsela jurada a alguien, tenerla tomada con alguien, verlas venir

Con todo, existe alguna forma en masculino, si bien aquí también es posible encontrar una tendencia hacia el femenino: pasarlo bien es casi exclusivo del español europeo, mientras que se prefiere pasarla bien en la inmensa mayoría de las variedades americanas. En algunos casos propuestos en la bibliografía para ejemplificar esta clase de clíticos, como por ejemplo tenerlos bien puestos 'tener arrestos' o tenérselo creído 'ser arrogante' es concebible que en la conciencia del hablante todavía haya un sustantivo masculino al que sustituye el clítico, o que se esté empleando el clítico para referir a una proposición u otro predicado, como sucede en Que es el mejor, se lo cree.

Los estudios previos también han discutido esta propiedad de los clíticos marginales españoles desde distintas perspectivas. Espinal (2009) lo relaciona con las formas neutras plurales del latín, superficialmente homófonas al femenino, en armonía con su propuesta de que los clíticos marginales denotan entidades abstractas. García Page (2010), sin embargo, nota que la existencia de formas plurales del clítico invalida toda asociación contemporánea con el neutro -ya que el neutro español carece de plural-, y propone -creemos, que de forma correcta- que la preferencia por el femenino debería relacionarse con otros casos de fraseología del español donde emergen femeninos anómalos, como son los de (9).

$$
\begin{aligned}
& \text { a. a pies juntillas } \\
& \text { b. a hurtadillas } \\
& \text { c. a gatas }
\end{aligned}
$$

En (9a), pese a que pies es masculino, se verifica el uso del femenino en el adjetivo juntillas. En el análisis que proponemos en este trabajo, la razón de que el clítico esté fijado y que tenga una marcada preferencia por el femenino se deben al mismo motivo: el clítico está manifestando rasgos del nombre silencioso de MANERA, que es femenino. Este mismo sustantivo silente, como argumentaremos, está detrás de las construcciones de (9), y otras relacionadas.

\section{Propiedades morfológicas, sintácticas y semánticas de los clíticos marginales y de sus estructuras}

En esta sección vamos a mostrar las propiedades fundamentales de la construcción en la que interviene el clítico marginal; comenzaremos con sus propiedades sintácticas y seguiremos con las propiedades semánticas y morfológicas.

\subsection{Propiedades sintácticas}

Espinal (2009, pp. 1231-1237) detalla una serie de propiedades sintácticas, algunas de las cuales son exclusivas de los clíticos marginales en catalán -por ejemplo, la incorporación explícita del clítico dentro del verbo- o no se aplican a todos los casos conocidos - por ejemplo, la fijación en caso, que es discutida en Leivada y Grohmann (2014)-. Aquí nos centraremos en las propiedades que se aplican de forma más general a los casos españoles, que constituyen el tema fundamental de este artículo. 
Una primera restricción sintáctica es que solo puede existir un clítico marginal por construcción. Nótese que en los casos en los que aparece otro clítico, este sí tiene propiedades referenciales y puede aparecer en primera o segunda persona. Varias expresiones españolas contienen un reflexivo, como es el caso de las de (10).

(10) dárselas de algo 'fingir tener propiedades que no se tienen', pirárselas 'huir apresuradamente'

En este caso el reflexivo puede aparecer en cualquier persona y número; la presencia de este reflexivo se relaciona con el significado conceptual de las expresiones, que hablan de situaciones que afectan al propio sujeto y no son transferibles a una entidad externa.

(11) a. De vez en cuando me las doy de peligrosa. [bvd.sid.cu, ap. Corpus del español]

b. Te las diste de valiente. [iniciativadebate.org, ap. Corpus del español]

c. Se las da de liberal. [agaviria.blogspot, ap. Corpus del español]

d. A menudo nos las damos de vivos. [evitandointensidades.blogspot, ap. Corpus del español]

e. ...que os las deis de listillos. [micropsia.otroscines, ap. Corpus del español]

f. Aparte se las dan de comediantes. [ciudadanosenred.mx, ap. Corpus del español]

En otros casos (véase García Page, 2008, 2010, p. 137 para una taxonomía más detallada), la expresión implica alguna noción de transferencia, y en tales casos aparece un clítico dativo, de nuevo con propiedades referenciales. Este es el caso, por ejemplo, de jugársela a alguien 'estafar a alguien':

(12) a. Si el tiempo te la juega, igual te hielas. [blogs.elpais.com, ap. Corpus del español]

b. Se la juega a otro amigo. [conspiralocura.blogspot, ap. Corpus del español]

c. Me la jugaron descaradamente. [blogdelpadrefortea.blogspot, ap. Corpus del español]

d. Dos deseos que nos la juegan. [caminohacialafelicidad.com, ap. Corpus del español]

e. Qué chungas haciendo esquelas de los que os la jugaban [opinionesincorrectas.com] f. Quien se la juega a todos es la hiena. [foro.telenovela-blog.com, ap. Corpus del español]

Por tanto, el clítico marginal es único dentro de una expresión dada.

Una segunda propiedad que ha discutido detalladamente Espinal (2009) es que la presencia del clítico -marcado morfológicamente como acusativo- tiene un efecto intransitivizador de la estructura: pese a la ausencia de papel referencial, y a que es imposible asignarle un papel temático al clítico, no pueden aparecer complementos directos que de otra manera el verbo podría haber introducido.

(13) a. liarse un cigarro

b. *liarla un problema

(14) a. jugarse un premio

b. *jugársela un premio

a. arreglarse el pelo

b. *arreglárselas el pelo 
Espinal (2009) relaciona esta propiedad intransitivizadora con la incorporación que propone que tiene lugar entre el clítico y el verbo: al incoporarse, el clítico inactiva la posición argumental que correspondería al complemento directo. Ya que en nuestro análisis no aceptamos que esta incorporación se dé para el español, surge la pregunta de a qué se debe este patrón: lo discutiremos en la cuarta parte del artículo.

Una propiedad que no observa Espinal (2009) es que la presencia del clítico marginal puede permitir que un verbo auxiliar - por tanto, sin suficiente contenido conceptual para funcionar en ausencia de un verbo auxiliado- actúe como un verbo pleno. Este es el caso de (16), donde se puede comprobar que sin el clítico la expresión es imposible en ausencia de otro verbo.

(16) a. $*_{¡} H$ Haberse al fin con hombres de veras!

b. ¡Habérselas al fin con hombres de veras! [literaryjournal.wordpress.com, ap. Corpus del español]

Una respuesta trivial a este contraste podría ser que -sencillamente- la información conceptual suficiente está asociada a la estructura completa, no al verbo únicamente, pero Leivada y Grohmann (2014) dan argumentos de que a nivel estructural la construcción idiomática no debe considerarse atómica, y por lo tanto esto sugiere que ya en la estructura sintáctica el clítico debe ser capaz de aportar suficiente información para que el verbo auxiliar complete su significado.

De manera similar, y esta propiedad sí es discutida en Espinal (2009), algunas expresiones con clítico marginal contienen verbos que para la mayoría de los hablantes no pueden funcionar fuera de esa construcción. El DRAE identifica diñar como una expresión del caló usada con el significado de dar (cf. endiñar), pero para muchos hablantes este verbo no puede aparecer usado solo, y solo cuando el clítico se asocia con la expresión tiene significado conceptual suficiente (diñarla 'morir').

En último lugar, contra Espinal (2009), se comprueban casos en que el clítico marginal puede asociarse con un cuantificador universal. Hay al menos dos expresiones de este tipo donde es necesario que aparezca todo (17) y Silva Garcés (2017) aporta ejemplos del español argentino donde también se da esta situación (18).

a. sabérselas todas

b. no tenerlas todas consigo

a. Este viernes a careterarla toda.

b. Hoy está para michaelscottearla toda.

[ap. Silva Garcés, 2017, p. 55, ejs. 23a, 23b]

La concordancia entre el clítico y el cuantificador tanto en género como en número indican de forma directa que el segundo cuantifica sobre el primero. De forma interesante, como nota Silva Garcés (2017, p. 56), la cuantificación no opera sobre la duración del evento, sino sobre la intensidad en que sucede el comportamiento descrito por el verbo. Así, caretear significa 'que se comporta como un careta, alguien falso y fingidor' y correlativamente caretearla toda implica que este comportamiento falso se lleva a un altísimo grado de intensidad. Esto es lo que esperamos, de hecho, si el clítico corresponde a un componente de manera, ya que en tal caso la cuantificación que opera sobre él debe indicar, de forma predecible, que esa manera es llevada a un extremo. Este mismo valor de manera es rastreable en el significado idiomático de (17a) y (17b): (17a) se refiere a un rasgo del carácter de una 
persona que le hace funcionar bien en situaciones que se producen de cualquier manera concebible, y (17b) alude, de manera similar, a una situación en la que no todas las maneras en las que algo podría desenvolverse dan suficiente confianza al sujeto.

La existencia de estos casos de cuantificación y concordancia entra en contradicción con la caracterización que hace Espinal (2009) de estos clíticos al menos en el sentido de que, en su propuesta, cuando el clítico se incorpora deja de ser un elemento sintáctico independiente que pueda referir o estar en una relación formal con palabras de fuera del núcleo verbal. Esto constituye, pues, un argumento empírico de que la propuesta de la incorporación debe ser revisada.

\subsection{Propiedades semánticas}

Pasemos ahora a las propiedades semánticas de las construcciones. Junto al hecho ya apuntado de que el clítico es no referencial, no tiene un papel temático definido y no es fácil asociarlo siempre con un sustantivo concreto al que pueda sustituir, una primera propiedad relevante -que hasta donde se nos alcanza no ha sido discutida detalladamente en la bibliografía- es que cuando se compara la versión no idiomática del verbo con aquella que incluye al clítico marginal, la segunda incorpora un componente de manera, a veces relacionado con un comportamiento. Este significado de manera es rastreable incluso a pesar del valor conceptual idiomático de la estructura. Véase el par de (19).

(19) a. Por lo pronto Karmele se piró de la actividad. [blogs.20minutos.es, ap. Corpus del español]

b. Después Floripondia se las piró de ahí. [epa.com.py, ap. Corpus del español]

El verbo pirarse, de carácter coloquial, cuando aparece sin clítico indica simplemente abandonar un lugar. No indica cuál es la manera en que se abandona, y concretamente si salir del lugar se produce de manera apresurada o no. En el caso de (19b), en cambio, es claro que la acción tiene que darse de forma apresurada, de tal forma que el predicado no se siente como adecuado si el sujeto remolonea antes de marcharse del lugar.

Esta asociación con el componente de manera es evidente en los casos productivos del español de Argentina descritos en Silva Garcés (2017), donde sistemáticamente los nombres empleados en la derivación de los verbos se interpretan como predicativos o modales (Martín García, 2008). En el primer grupo, el sustantivo se toma como un modelo de comportamiento que sigue el sujeto, actuando así 'a la manera de' la entidad que denota.

(20) tontearla, fanfarronearla, riquelmearla

En el segundo grupo, el sustantivo denota directamente una manera de ejecutar una acción: cuchichearla, secretearla, parrandearla

Fuera de esta variedad, donde la construcción es completamente productiva si se da la semántica de manera, el componente de manera y comportamiento humano es visible en la mayor parte de las construcciones que contienen un clítico marginal:

(22) agenciárselas, apañárselas, armarla, arreglárselas, bandeárselas, cagárselas, cazarlas al vuelo, colársela, componérselas, dársela con queso, dárselas de algo, emprenderla 
con alguien, entendérselas con alguien, envainársela, fliparlo, gastárselas, gozarla, habérselas con alguien, ingeniárselas, joderla, jorobarla, jugársela, liarla, pagárselas, pasarlo, pifiarla, sabérselas todas...

Pese a su valor idiomático, todas estas expresiones contienen un significado en que el sujeto debe tener cierta actitud hacia algo, que le lleva a actuar de una manera definida -buena, mala, agresiva, habilidosa...- en una situación o con una persona, o bien la construcción indica una manera de percibir un estímulo concreto, dependiendo del estado psicológico que produce.

Son muy pocas las construcciones de este tipo en que resulta menos obvio el valor de manera, e incluso en tales casos es posible rastrearlo indirectamente. Por ejemplo, de entre la lista de expresiones con clítico marginal que lista para el español peninsular ${ }^{4}$ Cifuentes Honrubia (2017), destaca la clase de expresiones que indican 'morir', algo que aparentemente no implica una manera definida.

diñarla, palmarla, espicharla, entregarla

En estas estructuras cabría pensar que el concepto idiomático impide que se perciba el componente de manera, pero pese a todo se puede construir una argumentación que hace más perceptible esta noción. Como ya hemos apuntado, diñar es una forma caló relacionada con $d a r$, por lo que originalmente el verbo indicaba transferencia, al igual que entregar. En el caso de palmar, aisladamente indicaba una forma jergal de indicar dar un golpe-como espichar, "punzar con un objeto agudo"5-, lo cual también puede interpretarse como una transferencia. En estos predicados, la transferencia se ha reinterpretado como una forma de dejar de tener algo de una manera concreta, la de pasar de un estado vivo a uno muerto, lo cual puede considerarse sin esfuerzo una manera de desprenderse de algo.

Dado, sin embargo, que estamos ante construcciones idiomáticas, es necesario aportar alguna prueba independiente de la existencia de este componente de manera. Las maneras se asocian a las entidades animadas -por extensión también a los agentes teleológicos que inician un proceso por sus propiedades internas (Harley y Folli, 2008)-, en la medida en que solo las entidades animadas pueden controlar la manera en que se desarrolla un proceso, se obtiene un resultado o se experimenta una situación. De forma interesante, todas las estructuras idiomáticas con clítico marginal exigen que el sujeto sea animado, y preferentemente humano, independientemente de que el verbo, sin clítico, en su lectura literal admita sujetos de otros tipos.

Veamos por ejemplo el caso de jorobar frente a jorobarla; como se ve en (24a), sin el clítico el verbo admite sin dificultad un sujeto no animado que actúa como causante y por ello solo inicia el proceso, sin controlar la manera en que se desarrolla. (24b) muestra que con el clítico ese sujeto es imposible, y es necesario uno animado (24c); proponemos que esto es porque la construcción idiomática necesita un componente de manera para interpretarse correctamente. De forma interesante, jorobar admite una forma anticausativa (jorobarse) donde el sujeto experimenta el proceso por sus propiedades internas, pero jorobarla no admite una forma *jorobársela, porque debe expresar una actividad controlada externamente.

(24) a. Cuando las leyes son [...]ignoradas si joroban al gobierno de turno.

[labestiapolitica.blogspot.com, Corpus del español]

b. \#Las leyes la joroban.

c. Como nos miran con esa carita, les echamos y la jorobamos.

[mundoanimalia.com, Corpus del español] 
Otro caso del mismo paradigma es pirarse, que indica solo movimiento direccional, frente a pirárselas, que requiere una manera rápida:
a. La pasta se piró.
[cubasindical.blogspot.com, Corpus del español]
b. *La pasta se las piró.
c. Juan se las piró.

Sucede lo mismo con arreglar frente a arreglárselas (26) o con traer frente a traérselas con alguien (27).

(26) a. Esto arreglará el problema. [educandoamihijo.com, Corpus del español]

b. *Esto se las arregló.

c. Juan se las arregló.

(27) a. Diciembre o enero trae un suspiro de alivio. [espanol.mapsofworld.com, Corpus del español]

b. *Diciembre o enero se las trae con mi hermana.

c. Juan se las trae con mi hermana.

Pasemos a la última sección, en la que nos detendremos en las propiedades morfológicas de los verbos involucrados en las construcciones con clíticos marginales.

\subsection{Propiedades morfológicas}

Silva Garcés (2017) estudia detalladamente la clase de afijos verbalizadores que pueden emplearse en las estructuras que nos ocupan, y destaca que la clase productiva se asocia generalmente al sufijo -ear, frente a otros disponibles, como -ecer, -ificar o -izar. Esta apreciación, hasta donde se nos alcanza, es completamente correcta: no hemos documentado en las enumeraciones más exhaustivas de estas estructuras (García Page, 2010; Cifuentes Honrubia, 2017) ni un solo ejemplo de construcción con clítico marginal en que el verbo tome como verbalizador uno de estos sufijos. Los verbos o bien son morfológicamente simples siguiendo la estructura de una raíz con una vocal temática- o bien usan, como predice Silva Garcés, el sufijo -ear.

Este autor nota también que las formaciones en -ear que admiten el clítico marginal no pertenecen a cualquier clase de las que produce este verbalizador. Concretamente (Silva Garcés, 2017, p. 40), las clases de verbos resultativos (28), modificados (29), instrumentales (30) y locativos (31) (siguiendo la clasificación de Martín García, 2008) están excluidas de estas construcciones -salvo que se reinterpreten como maneras, como en el caso de callejearla, que habla de un tipo de comportamiento humano y no de un lugar-:

(28) agujerear, trocear

(29) babear, coplear

(30) cornear, gasear

(31) callejear, bordear

Crucialmente, Silva Garcés (2017) relaciona ambas propiedades con el componente de manera: específicamente, sigue la propuesta de Oltra-Massuet y Castroviejo (2014) por la cual las formaciones predicativas (tontear) y modales (secretear) de los verbos en -ear contienen en su estructura subyacente una preposición de manera (32). 


$$
\left[\mathrm{Sv} \quad[\mathrm{Juan}]_{\mathrm{i}} \quad \mathrm{v} \quad\left[\mathrm{SP}^{\mathrm{manera}}[\mathrm{PRO}]_{\mathrm{i}} \quad \mathrm{P}^{\text {manera }}[\text { Raíz }]\right]\right.
$$

La intuición fundamental es que las formaciones con clítico marginal se relacionan directamente con la manera: el sufijo que puede indicar esta noción en los verbos del español es -ear, lo cual explica que otros verbalizadores estén excluidos. Es decir: -ear es la materialización morfológica de la preposición de manera y el núcleo verbal. Los verbos, pues, o son morfológicamente simples o contienen -ear, pero no hay más opciones. Por otro lado, no todas las formaciones en -ear indican manera, de forma que las clases a las que se restringe la construcción deben ser necesariamente aquellas en que el sustantivo de la base se interpreta o como patrón de un comportamiento o como un modo de ejecutar una acción, excluyendo por ejemplo las formaciones en que el sustantivo denota la entidad que se obtiene como resultado de un proceso (29).

En nuestro análisis, partimos de la idea de que Silva Garcés (2017) está en lo cierto, en esencia, dentro de su interpretación de estos verbos, y sobre todo en identificar formalmente la importancia de la noción de manera, como también hace desde otro punto de vista García Page (2010). No obstante, como mostraremos a continuación, el análisis expreso que presenta Silva Garcés (2017), aunque compatible mejor que el de Espinal (2009) con ciertos hechos, no captura de forma completa los datos, por lo que propondremos una explicación alternativa.

\section{Un sustantivo silencioso de MANERA}

Silva Garcés (2017), en esencia, propone la estructura de (33) -que construye sobre Oltra-Massuet y Castroviejo (2014)- para los clíticos marginales.

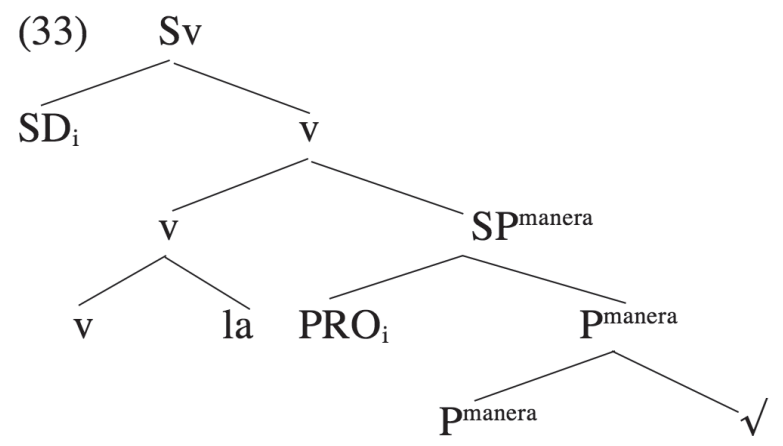

En esta estructura, la proyección verbal recibe una interpretación como 'comportarse', y la manera en que se ejecuta el comportamiento está precisada por el sintagma preposicional (SP) con significado de manera, que toma como complemento la raíz del verbo y como especificador un pronombre tácito que refiere al sujeto del verbo, que es quien controla esa manera. Como se ve, el clítico marginal se trata como un adjunto al núcleo verbal de comportamiento. Este autor supone, de forma completamente estándar en el modelo, que se produce un movimiento de núcleos por el que la raíz primero se incorpora a la preposición, y luego todo el complejo se incorpora al núcleo verbal.

Esta propuesta, donde el clítico no se incorpora al verbo sino que se genera como un adjunto al núcleo, predice correctamente que ese elemento está activo para procesos de concordancia con cuantificadores, como es el caso con todo en los ejemplos observados en la sección 2.1 de este artículo. 
No obstante, hay varios motivos por los que no aceptaremos esta estructura y propondremos una alternativa. Comenzando por el principal de ellos, esta propuesta no deriva el hecho de que exista una tendencia tan marcada a que los clíticos marginales aparezcan en femenino en español.

En segundo lugar, asociar el clítico al verbalizador no captura de forma directa la asociación directa con el componente de manera que muestran los datos, o la propia elección de verbalizadores cuando estos aparecen manifestados morfológicamente en la estructura. ¿Qué impediría que el mismo clítico se adjuntara por ejemplo a un núcleo verbal cuyo complemento no fuera de manera? Para que la correlación quedara recogida de forma clara en la estructura, parece claro que de alguna manera ese clítico tiene que asociarse al SP que expresa dicha manera, no al núcleo que simplemente aporta la noción de que la estructura completa pertenece a la clase léxica de los verbos. Desde esta perspectiva, la estructura propuesta sobregenera los datos.

En tercer lugar, y esta es una crítica que se aplica también a Oltra-Massuet y Castroviejo (2014), no parece apropiado proponer para el español que existe un núcleo preposicional que denote directamente maneras, que es lo que indica tratar el SP como una estructura que nuclearmente aporta este significado. En primer lugar, no hay candidatos claros en el sistema preposicional del español para este significado de manera: elemento que se acerca es como, pero junto a usos que pueden ser descritos como maneras de actuar (34a), también tiene incluso cuando toma nombres como complemento- usos que son más difíciles de considerar 'maneras' en sentido estricto (34b, 34c) dado que no admiten paráfrasis como 'a la manera de' (RAE y ASALE, 2009, p. 1620).

a. Tu alma / Ser superior actúa como tu banquero personal. [elmistico.com.ar, ap. Corpus del Esp.]

b. Soy un dolor antiguo como el mundo. [revistadepoesia.wordpress.com, ap. Corpus del Esp.]

c. Tuvo que jugar como volante de contención. [clubbolivar.blogspot.com, ap. Corpus del Esp.]

d. El hombre utiliza la razón como último recurso. [res.uniandes.edu.com, ap. Corpus del Esp.]

De igual manera, las maneras tienden a expresarse más habitualmente con otras preposiciones, entre las que destaca $a$, junto a otras:
a. a mano
b. a la italiana
c. a hurtadillas
d. de puntillas
e. de rodillas
f. con deferencia
g. con facilidad

Claramente, estas otras preposiciones tienen usos en que no denotan maneras (a casa, de plástico, con una llave), lo cual pone en duda que para el caso del español exista un núcleo preposicional concreto que denote por sí mismo manera. Parece, más bien, que el conjunto formado por la preposición y el sustantivo denota una manera dependiendo de la naturaleza del complemento. 
Todos estos motivos nos llevan a proponer la siguiente estructura: no existe un núcleo $\mathrm{P}$ de manera, sino que la lectura de manera de un sintagma depende de que este tome como complemento un sustantivo que tenga esta información, y en el caso concreto de las estructuras con clítico marginal, esa información la proporciona un sustantivo silencioso MANERA (Kayne, 2005a) (36). Discutiremos detalladamente esta estructura en el cuarto apartado, sobre todo en lo que toca a la legitimación del sustantivo MANERA y las implicaciones semánticas de la estructura.

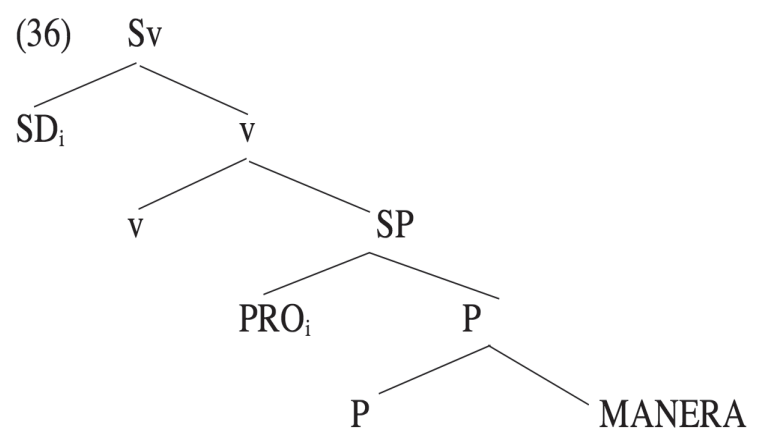

El clítico marginal es la materialización de este sustantivo silente cuando se dan condiciones sintácticas específicas a las que nos referiremos en el cuarto apartado de este artículo. La razón de que ese clítico sea casi siempre femenino es que el sustantivo silente MANERA, como su versión explícita, es femenino. La razón de que los clíticos marginales impongan la lectura de manera a la construcción, y pidan sujetos animados como consecuencia, es trivialmente que el propio clítico designa al sustantivo MANERA. Por tanto, el clítico tiene semántica y es una unidad independiente dentro de la estructura, lo cual permite que se separen y sean cuantificados por una expresión como todo; asimismo, ya que el sustantivo designa una manera, esperamos correctamente que la cuantificación que incida en él compute la intensidad del comportamiento descrito por el verbo. Vayamos por partes.

\subsection{Los nombres silentes en Kayne}

La atención reciente que han recibido en el análisis sintáctico las variantes silentes de los sustantivos se debe en buena medida a Kayne (cf. sobre todo Kayne, 2004, 2005a, 2005b, 2007, 2008, 2009). En su propuesta las lenguas naturales cuentan con versiones silentes de algunos sustantivos que designan nociones conceptuales básicas, como LUGAR, NÚMERO, CANTIDAD, AÑO, COLOR o PERSONA. Revisemos aquí parte de su argumentación.

Un argumento directo de la existencia de un sustantivo silente NÚMERO se encuentra en el siguiente paradigma del inglés (Kayne, 2005b). Una forma como few 'poco' se comporta como un adjetivo en la medida en que admite grados comparativo y superlativo.

$$
\begin{aligned}
& \text { a. few } \\
& \text { 'poco' } \\
& \text { b. few-er } \\
& \text { poco-comp } \\
& \text { 'menos' }
\end{aligned}
$$




$$
\begin{aligned}
& \text { c. few-est } \\
& \text { poco-sup } \\
& \text { 'lo menos' }
\end{aligned}
$$

Pero dado esto, resulta sorprendente que few pueda emplearse con el artículo indefinido, que requiere sustantivos en singular.

$$
\begin{aligned}
& \text { a few books } \\
& \text { un poco libros }
\end{aligned}
$$

Kayne (2005b) propone que en realidad, no hay nada irregular en la estructura: $a$ 'un' mantiene sus condiciones de selección sintáctica normales y few 'poco' sigue siendo un adjetivo, porque está presente un sustantivo silente equivalente a NÚMERO. La sintaxis de (38) es (39).

$$
\begin{aligned}
& \text { a few NUMBER (OF) books } \\
& \text { un poco número de libros } \\
& \text { 'un número pequeño de libros' }
\end{aligned}
$$

Podría suponerse que algo semejante sucede en el español en el paradigma de (40). En (40a) se confirma que el cuantificador concuerda con el sustantivo, por lo que no tiene naturaleza nominal. (40b) muestra que puede combinarse con el artículo indefinido, y que en tales casos es invariable en género (40c). Todo esto podría llevar a la conclusión de que la estructura es más bien como la de (40d).

$$
\begin{aligned}
& \text { a. pocos libros } \\
& \text { b. un poco } \\
& \text { c. un poco de agua } \\
& \text { d. un poco NÚMERO de agua }
\end{aligned}
$$

Otro ejemplo ilustrativo implica al sustantivo silente AÑOS (Kayne, 2005b), que en el análisis de Kayne subyace a una estructura como la de (41).
a. That child is ten.
ese niño es diez
'Ese niño tiene diez años'
b. That child is ten YEARS
ese niño es diez años

El equivalente literal español no está disponible con esta interpretación, lo cual sugiere que o bien el español carece de este sustantivo silente, o que no está legitimado en estos contextos. Donde el español y el inglés coinciden es en las construcciones que permiten inferir la existencia de un sustantivo HORA.

$$
\begin{aligned}
& \text { a. It is three HOURS o'clock } \\
& \text { b. Son las tres HORAS }
\end{aligned}
$$

Este último ejemplo ilustra también que, según esta hipótesis, la presencia del sustantivo silente se puede rastrear en el hecho de que los determinativos y adjetivos recogen el género y número que exhibe, pese a no aportar información fonológica. Precisamente esta 
propiedad es la que nos permite, en nuestra propuesta, justificar que el clítico marginal tienda a ser femenino, ya que MANERA, como su equivalente con sonido, sería femenino. Pasemos ahora, en la siguiente sección, a mostrar que este sustantivo plausiblemente se encuentra en otras construcciones del español contemporáneo.

\subsection{Extensión de MANERA a otras estructuras}

García Page (2010) relaciona directamente que los clíticos sean femeninos con la tendencia general del español a tener construcciones con significado de manera donde el género también es femenino. En esta sección vamos a revisar una serie de estructuras, para mostrar que es plausible que el sustantivo silente MANERA también está presente en estos casos.

Comenzando por la más clara de ellas (43), en español contemporáneo es frecuente que se formen construcciones de manera con un artículo determinado femenino y un adjetivo gentilicio también femenino; la preposición es $a$ en estos casos. Hay algún caso en que se documentan adjetivos de otros tipos (43e), aunque la estructura es productiva solo con los gentilicios.
a. a la italiana
b. a la francesa
c. a la riojana
d. a la española
e. a la desesperada

La concordancia y la presencia del determinativo quedan explicadas inmediatamente si se propone que el sustantivo silente está presente en estos casos.

$$
\text { a la MANERA italiana }
$$

Hay otros casos con la misma estructura donde en lugar del adjetivo gentilicio aparece un nombre propio. Incluso pese a la presencia de este nombre propio, se mantiene la propiedad de que el artículo es femenino -junto al hecho anómalo de que el artículo aparezca con el nombre propio sin que se den las asociaciones sociolingüísticas que tienen expresiones como el Paco en español general-.
a. una película a la Kubrick
b. una sinfonía a la Mozart
c. unos espaguetis a la Ferrán Adriá

De nuevo, las propiedades anómalas de la construcción quedan explicadas si se propone un sustantivo silente MANERA que explica la presencia del determinativo y su concordancia femenina.

\section{a la MANERA Kubrick}

En segundo lugar, hay una segunda clase de locuciones de manera donde García Page (2010) nota que se produce un marcado anómalo en femenino pese a que el sustantivo que aparece no se emplea fuera de la estructura en femeninio, o el sustantivo que aparece materializado expresamente no es femenino. 
(47)
a. a pies juntillas
b. a derechas
c. a tontas y a locas
d. de buenas a primeras
e. a \{hurtadillas / escondidas / las calladas\}
f. a gatas
g. de puntillas
h. en volandas
i. a tientas

La concordancia en femenino de juntillas en (47a) deja de serlo si suponemos que el significado de manera no lo aporta la preposición, como ya hemos argumentado, sino un sustantivo silente MANERA que en este caso, por fijación de la estructura idiomática, aparece en plural. Lo mismo puede suponerse en (47b), (47c), (47d) y (47e), que difieren mínimamente de (47a) solo en que en ellas la construcción no incluye un segundo sustantivo.

En el resto de casos, tenemos expresiones cuya peculiaridad es que junto a la preposición hay un sustantivo que fuera de la locución de manera o bien no aparece como femenino plural (tiento $\sim$ tientas), o bien no existe fuera de esa locución (volandas), o bien aunque admitan formas femeninas plurales en otros casos, están fijadas así en la locución. En todos estos casos proponemos que la terminación -as está fijada así porque materializa los rasgos de género y número del sustantivo silente MANERA, en plural. Ilustramos la propuesta concreta con el caso de tientas: tratamos tient- como una raíz que modifica al sustantivo MANERA.

\section{(48) $\quad[\mathrm{SP}$ a $\quad[$ SNúmero $-\mathrm{s} \quad[\mathrm{SN}$ [tient-] MANERA] $]$}

De esta manera, la restricción sería que cuando el nombre silente MANERA lleva una raíz que lo modifica -véase Kayne (2008) para el tratamiento de algunos elementos deícticos como modificadores de nombres silenciosos-, al menos deben materializarse de él los rasgos de género y número asociados.

\section{Estructura sintáctica del clítico: detalles y extensiones}

Nuestra propuesta es, por tanto, que el mismo sustantivo MANERA que aparece en las locuciones señaladas arriba es el que se asocia al clítico marginal que aparece en las construcciones verbales. Esto explica por qué existe la tendencia al femenino, pero aún no hemos explicado las propiedades que impone la estructura verbal. Esta sección se dedica a ello.

\section{1. $\quad$ Marcado y propiedades}

Recordemos la estructura que hemos propuesto para los casos relevantes.

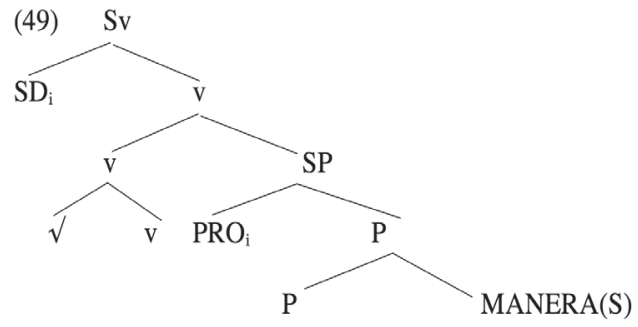


Siguiendo a Acedo-Matellán (2010) (cf. también Acedo-Matellán y Mateu, 2014) adjuntamos la raíz a la proyección verbal, en lugar de tratarla como un complemento de P, como hacen Oltra-Massuet y Castroviejo (2014). Alternativamente, se puede asumir Ramchand (2008) en su propuesta de que las raíces no constituyen núcleos separados, y que son un efecto de la inserción de exponentes que se asocian a las estructuras sintácticas abstractas.

En esta sección mostraremos cómo la estructura explica que (i) la materialización de MANERA sea un clítico, (ii) el verbo se intransitivice, y (iii) el clítico no pueda asociarse a ningún papel temático del verbo.

Comenzando por la primera, asumimos Ormazábal y Romero (2013) en su propuesta de que un elemento que actúa como complemento de un SP recibe caso de la preposición salvo que la preposición se incorpore al verbo, en cuyo caso es el complejo $\mathrm{P}+\mathrm{v}$ el que asigna caso al complemento. En estas construcciones, existe evidencia independiente de que $\mathrm{P}$ pierde su independencia con respecto al verbo, ya que nunca emerge la preposición que introduce el complemento de manera. Proponemos, pues, que se produce una incorporación de $\mathrm{P}$ a v, como se muestra en (50).

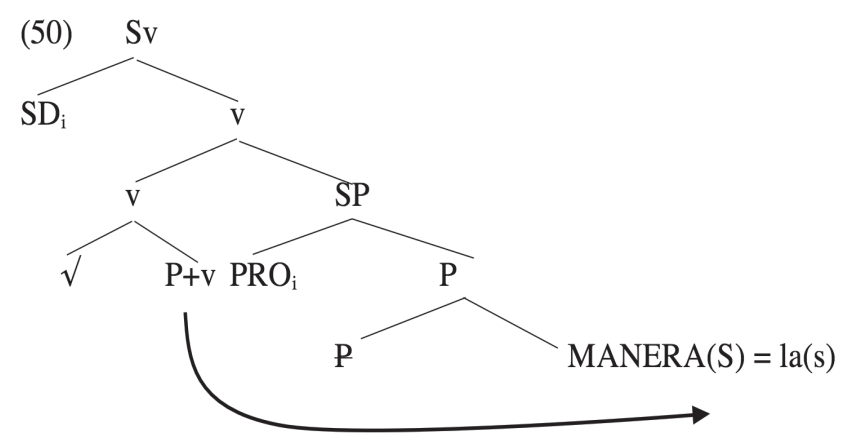

En esta configuración, P no puede asignar caso, y por tanto esperamos que sea el verbo el que tenga que legitimar al sustantivo con significado de MANERA. Consecuentemente, la materialización del sustantivo es -bajo condiciones de variación a las que nos referiremos en el siguiente apartado- la de un clítico acusativo.

Esta misma secuencia explica que el verbo se intransitivice: en la suposición estándar de que el complemento directo de un verbo transitivo se introduce como complemento de la proyección verbal, en (50) se comprueba que esa posición ya está ocupada por el SP donde se define una manera. Por este motivo, de forma directa, no cabe estructuralmente un complemento directo más; además, en correlación con la propiedad anterior, el verbo ha satisfecho ya su capacidad de dar caso, por lo que aunque se introdujera otro miembro de la estructura, este tendrá que estar marcado por una preposición (como pagárselas a alguien, o arreglárselas con algo).

La estructura también da cuenta de por qué el clítico que corresponde a MANERA no recibe ningún papel temático del verbo. No basta, creemos, con decir que la MANERA es solo un conjunto de propiedades (frente a Espinal, 2009), porque en último término es un elemento nominal que en principio podría llevar un papel temático; por ejemplo, su variante fonológicamente realizada puede llevar un papel temático -paciente, en (51)-.

(51) Juan cambió la manera en que cantaba. 
En nuestro análisis la razón de la ausencia de papel temático asociado al clítico marginal se reduce a que el sustantivo MANERA y el verbo no se generan en el interior del mismo sintagma, lo que impide que el verbo le asigne léxicamente un papel: MANERA es introducido como complemento de una preposición que se limita a relacionar un sujeto controlador con esa forma de ejecución, y su única relación formal con el verbo es la que atañe a su manifestación como acusativo.

\subsection{Variaciones}

Hay dos aspectos que queremos discutir antes de terminar este trabajo: el primero de ello se refiere al contraste de (52), que muestra un caso con clítico marginal en Argentina (tomado de Silva Garcés, 2017) frente al equivalente del español peninsular, donde no hay clítico marginal.
a. La secretean en las fiestas.

b. Secretean en las fiestas.

El segundo se refiere a los casos -menos frecuentes, pero existentes- donde aparece un clítico masculino, como son los de (53) -como se ha notado ya, la primera en alternancia con una construcción con clítico femenino, mayoritaria en América-. Siguiendo nuestra propuesta, estos no pueden ser manifestaciones de un nombre MANERA.
a. pasarlo bien
b. jugárselo todo a una carta
c. perdérselo
d. llevarlo claro
e. tenerlo \{claro / crudo\}
f. echarlo todo a perder
g. encontrárselo todo hecho

En el primer caso lo que encontramos, en términos descriptivos, es que hay una extensión mayor de los clíticos marginales en Argentina, pero la interpretación de las dos oraciones de (52) es equivalente en sus variedades respectivas. Estos clíticos son acusativos, por lo que es tentador relacionar esta extensión con un fenómeno de variación independiente, concretamente la posibilidad de doblar el complemento directo mediante un clítico (Jaeggli, 1986; Leonetti, 2008; Zdrojewski y Sánchez, 2014). En efecto, en la variedad argentina se pueden documentar casos como (54a), frente a (54b) en las variedades que no permiten el doblado.

a. La vi a mi hermana.

b. Vi a mi hermana.

Proponemos que (52a) y (54a) son paralelos, y se deben esencialmente a los mismos factores, que dependen en cada caso del análisis del doblado de clítico que se emprenda: el clítico puede tratarse como un modificador del nombre MANERA en estos casos -siguiendo la hipótesis del Sintagma Determinante Complejo de Uriagereka (1995)-, y la variedad argentina permite esta modificación en contextos que no son admisibles en otras variedades, dando lugar a una extensión mayor de estos clíticos acusativos. 
Pasando ahora al segundo problema, la pregunta que surge inmediatamente es a qué corresponde el clítico lo que aparece en estas estructuras. No parece que una solución sea proponer que aquí hay un nombre masculino elidido, porque -como apunta RAE y ASALE (2009, pp. 2649-2650)- estas construcciones nunca aparecen con el clítico plural masculino los. Esto sugiere de forma fuerte que en estos casos no tenemos un masculino en realidad, sino un neutro: los pronombres neutros en español carecen de plurales. Las formas esos, aquellos, ellos y estos no son los plurales de los neutros (55), sino de los masculinos (56).
a. eso
b. aquello
c. esto
d. ello
a. ese
b. aquel
c. este
d. él

Si las construcciones de (53) se tratan de forma que el clítico corresponda a un neutro, excluimos que sea el resultado de la pronominalización de ningún sustantivo, ya que no existen sustantivos neutros en español. En tales casos, creemos que sí se cumple la propuesta de Espinal (2009) de que el clítico se refiere a un conjunto de propiedades, que como sucede en otros casos pueden ser subsumidas en un pronombre neutro:
a. [Simpático $]_{i}$, Juan lo $l_{i}$ es.
b. [Venir a tiempo] $]_{i}$ sí que $l_{i}$ intenté.
c. [Que tengo mala prensa] sí que $l_{i}$ dijo.

Nótese, sin embargo, que la existencia de cuantificadores universales (cf. 53c, 53f, $53 \mathrm{~g})$ o adjetivos concordantes $(53 \mathrm{~d}, 53 \mathrm{e})$ va en contra de la propuesta de que este pronombre se incorpora semánticamente al verbo. De esta manera, para (53) se aplicaría un análisis como el de Bibis y Roverge (2004), en el que el pronombre neutro contiene rasgos interpretables y por ello denota una entidad abstracta sin poder referir a una de las actualizadas en el contexto discursivo.

\section{Conclusiones}

Es el momento de esbozar las conclusiones principales. En este trabajo, hemos extendido y modificado el análisis de los clíticos marginales del español que propone Silva Garcés (2017) a los casos en que no es tan evidente el componente de manera. Hemos propuesto que la razón de que estos clíticos tengan una preferencia marcadas por el femenino es que se asocian con un sustantivo silente MANERA que, como su versión explícita, es femenino. De aquí se siguen numerosas propiedades de estas estructuras, como son la necesidad de que los sujetos sean animados, que la cuantificación sobre el clítico hable de la intensidad en que sucede un comportamiento, que sea posible en femenino que el clítico aparezca en plural, o que esa misma tendencia al femenino aparezca en otras locuciones de manera. La extensión más amplia de los clíticos marginales en Argentina se reduce a que esta variedad permite materializar el clítico acusativo en más contextos que la variedad peninsular, y los casos de aparente masculino han sido tratados como pronombres neutros con rasgos interpretables. 
Por tanto, si los resultados de esta investigación son correctos, no hay motivos para tratar estos pronombres marginales como expletivos. Su género es perfectamente predecible a partir del género del sustantivo que representan, y pese al carácter idiomático de estas construcciones su aportación composicional es rastreable en la selección de argumentos y los significados preferidos en estas estructuras.

Nuestra investigación tiene implicaciones para dos problemas clásicos de los estudios sobre las relaciones entre sintaxis y semántica:

(i) ¿Existen elementos que realmente carecen de significado? Si la sintaxis es un sistema combinatorio que construye estructuras que serán interpretables en la interficie sintáctica (Chomsky, 1995) o debe considerarse como un sistema simbólico (Langacker, 2000), entonces resulta poco intuitivo proponer que parte de los elementos que maneja la sintaxis para establecer sus estructuras carezcan de significado. Una parte de dichos elementos son los aparentes pronombres expletivos, una parte de los cuales hemos argumentado en este trabajo que no carecen de significado y por lo tanto no pueden ser considerados expletivos en sentido estricto. Resultaría interesante continuar esta línea de investigación para plantearse si otras operaciones generalmente consideradas como semánticamente vacuas realmente lo son, como sería el caso de la concordancia. Al menos por lo que toca a los resultados de este trabajo, hemos argumentado que los rasgos de número y género del clítico no son un efecto arbitrario sin implicaciones semánticas, sino que se deben a la clase de sustantivo que sustituyen.

(ii) ¿Están las construcciones idiomáticas completamente fosilizadas? Pese a que tradicionalmente se tiende a considerar que las expresiones idiomáticas han de tratarse como hechos de léxico en los que la sintaxis tiene poco que decir, estudios como Marantz (1984), McGuinnis (2002), y Mishani-Uval y Siloni (2016; cf. también Horvath y Siloni, 2009; Horvath, Klunover, Siloni y Wexler, en prensa) sugieren que el análisis más apropiado de las construcciones idiomáticas no puede dejar al margen las consideraciones sintácticas, algo sobre lo que centran su análisis Leivada y Grohmann (2014) en nuestro caso. Existen distintos motivos para proponer que lo que hace especial a una estructura idiomática es que no se establece una relación unívoca entre el contenido conceptual de cada constituyente separado y el significado de conjunto de toda la estructura, pero la contribución gramatical de cada uno de estos elementos sigue presente en la estructura idiomática y se refleja, entre otros aspectos, en el número de posiciones argumentales disponibles, la preservación del aspecto léxico del predicado y la sensibilidad de la estructura idiomática a los dominios sintácticos. Nuestro estudio incide en estos aspectos, al proponer que el componente de manera se conserva mediante -al menos- la necesidad de que exista un sujeto que controle externamente la eventualidad y la preferencia por los significados relacionados con comportamientos.

Estas cuestiones son, sin embargo, enormemente generales y su estudio deberá ser abordado de manera empírica y específica a través del tratamiento de distintos fenómenos. En este trabajo hemos tratado de aportar algo al estudio de solo uno de ellos.

\section{Notas}

1. Agradezco a José Luis Cifuentes Honrubia, Evelina Leivada y un revisor anónimo los comentarios a una versión previa de este trabajo. La investigación que subyace a este trabajo está financiada por el proyecto FFI2014-56968-C4-2-P, La variación en la interfaz sintaxis-discurso, del Ministerio de Economía y Competitividad de España. 
2. Según ASALE (2010), también se documentan pasarla de viva flor ('estar ocioso mientras otros trabajan', Guatemala y Nicaragua) y pasarla grueso ('disfrutar mucho', Honduras). Como pasarlo, 'consentir una mujer tener sexo con alguien', Chile.

3. Según ASALE (2010), en Venezuela el verbo se asocia con 'estafar a alguien'.

4. Como es de esperar en el estudio de las construcciones idiomáticas, existen diferencias en el significado de algunos de estos verbos en distintas variedades del español. De acuerdo a ASALE (2010), palmar(se) -sin clítico- significa 'pagar una deuda' en Argentina y Paraguay, 'morir' en Costa Rica, Nicaragua y Guatemala, y 'formirse' en Argentina. Un revisor anónimo nos informa de que en Costa Rica palmarla se interpreta como 'pasar la noche en blanco'.

5. En Colombia, el verbo significa 'pulsar, aplastar, oprimir'; 'desinflar un neumático' en Colombia, Venezuela y Bolivia, y ‘abrir un hueco’ en Puerto Rico.

\section{Bibliografía}

Acedo-Matellán, V. (2010). Argument structure and the syntax-morphology interface. (Tesis doctoral). Universitat Autònoma de Barcelona.

Acedo-Matellán, V. y Mateu, J. (2014). From syntax to roots. En A. Alexiadou, H. Borer y F. Schäfer (Eds.). The syntax of roots and the roots of syntax. (pp. 14-32). Oxford: Oxford University Press.

ASALE [Asociación de Academias de la Lengua Española]. (2010). Diccionario de Americanismos. Madrid: Santillana.

Biberauer, T. (Ed.). (2008). The limits of syntactic variation. Amsterdam: John Benjamins.

Bibis, N. y Roberge, Y. (2004). Marginal clitics. Lingua. 114, 1015-1034.

Bibis, N. (2002). The syntax of clitics in idiomatic and other fixed expressions. (Tesis doctoral). University of Toronto.

Borer, H. (Ed.). (1986). The syntax of pronominal clitics. New York: Academic Press.

Brucart, J. M., Gavarró, A. y Solá, J. (Eds.). (2009). Merging features. Oxford: Oxford University Press.

Chomsky, N. (1995). The Minimalist Program. Cambridge (Mass.): MIT Press.

Cifuentes Honrubia, J. L. (2017). El complemento directo lexicalizado. Congreso morfología y sintaxis (17 y 18 de julio de 2017). Universitat de Girona.

Cordero Monge, S. y Leoni de León, J. A. (2017). Locuciones verbales con clítico: ejemplos del español de Costa Rica. Actualizaciones en Comunicación Social. 1, 152-155.

Davies, M. (s.f.). Corpus del español. Recuperado de www.corpusdelespanol.org

Espinal, M. T. (2009). Clitic incorporation and abstract semantic objects in idiomatic constructions. Linguistics. 47, 1221-1271.

Fernández Soriano, O. y Táboas, S. (1999). Construcciones impersonales no reflejas. En I. Bosque y V. Demonte (Eds.). Gramática descriptiva de la lengua española. (pp. 17231779). Madrid: Espasa.

Harley, H y Folli, R. (2008). Teleology and animacy in external arguments. Lingua. 118, 190-202.

Horvath, J. y Siloni, T. (2009). Hebrew idioms. Brill's Annual Journal of Afroasiatic Languages and Linguistics. 1, 283-310. 
Horvath, J., Klunover, H., Siloni, T. y Wexler, K. (en prensa). Idiom storage and the lexicon. Journal of Linguistics.

García Page, M. (2008). Introducción a la fraseología española. Barcelona: Anthropos.

García Page, M. (2010). Locuciones verbales con clítico en español del tipo dársela. Verba Hispánica. 18, 135-145.

Jaeggli, O. (1986). Three issues in the syntax of clitics. En H. Borer (Ed.). The syntax of pronominal clitics. (pp. 15-42). New York: Academic Press.

Kayne, R. S. (2004). Here and there. En C. Leclère, E. Laporte, M. Piot y M. Silberztein (Eds.). Syntax, Lexis and Lexicon-Grammar. (pp. 253-273). Amsterdam: John Benjamins.

Kayne, R. S. (2005). Movement and silence. Oxford: Oxford University Press.

Kayne, R. S. (2005a). “A note on the syntax of quantity in English”. En Kayne: 176-215.

Kayne, R. S. (2005b). “Silent years, silent hours”. En Kayne: 241-261.

Kayne, R. S. (2007). Several, few and many. Lingua. 117, 832-858.

Kayne, R. S. (2008). Expletives, datives and the tension between morphology and syntax. En T. Biberauer (Ed.). The limits of syntactic variation. (pp. 175-217). Amsterdam: John Benjamins.

Kayne, R. S. (2009). Some silent first person plurals. En J. M. Brucart, A. Gavarró y J. Solá (Eds.). Merging features. (PP. 276-292). Oxford: Oxford University Press.

Langacker, R. (2000). Grammar and conceptualization. Berlin: De Gruyter.

Leivada, E. y Grohmann, K. (2014). Clitics in idioms: properties of morphosyntax and reference. Lingua. 150, 45-70.

Leonetti, M. (2008). Specificity in clitic marking and in differential object marking. Probus. 20, 33-66.

Martín García, J. (2008). Verbos denominales en -ear: caracterización léxico-sintáctica. Revista española de lingüística. 37, 279-310.

Marantz, A. (1984). On the nature of grammatical relations. Cambridge (Mass.): MIT Press.

McGuinnis, M. (2002). On the systematic aspect of idioms. Linguistic Inquiry. 33, 665-672.

Mendívil, J. L. (1999). Las palabras disgregadas. Sintaxis de las expresiones idiomáticas y los predicados complejos. Zaragoza: Prensas Universitarias de Zaragoza.

Mishani-Uval, Y. y Siloni, T. (2016). Ditransitive idioms in Hebrew. Natural Language and Linguistic Theory. 35, 715-749.

Oltra-Massuet, I. y Castroviejo, E. (2014). A syntactic approach to the morpho-semantic variation of -ear. Lingua. 151, 120-141.

Ormazábal, J. y Romero, J. (2013). Object clitics, agreement and dialectal variation. Probus. $25,301-344$.

RAE y ASALE. (2009). Nueva gramática de la lengua española. Madrid: Espasa.

Ramchand, G. (2008). First Phase Syntax. Cambridge: Cambridge University Press.

Ruiz Gurillo, L. (1997). Aspectos de fraseología teórica. Valencia: Universitat de València. 
Ruiz Gurillo, L. (2009). Liarla parda o la convencionalización de una unidad fraseológica. Español Actual. 91, 167-170.

Silva Garcés, J. (2017). Clíticos marginales en verbos denominales en -ear. Quintú Quimün. $1,34-60$.

Uriagereka, J. (1995). Aspects of the syntax of clitic placement in Western Romance. Linguistic Inquiry. 26, 79-123.

Zdrojewski, P. y Sánchez, L. (2014). Variation in accusative clitic doubling across three Spanish dialects. Lingua. 151, 162-176. 
